\title{
Classical Algebra: Matrix Multiplication (The Rule of Vacancies)
}

\section{Surajit Bhattacharyya*}

Seth Anandram Jaipuria College, University of Calcutta, West Bengal, India

\section{Reasons Behind the Work}

Author has completed his post-graduation in 1989. From then he kept himself engaged in guiding/helping the junior undergraduate students in various institutions and in his private coaching classes.

In the course of teaching, often he faced a problem. The students, specially the beginners, could not understand Matrix Multiplication easily. Though some students understood the topic in the first class, they asked questions in the next class. It was very confusing. He had to take classes for few consecutive days to make the idea clear to the students. Again, before examination they used to come to seeking help on the same topic repeatedly, it was very difficult for them to remember the process.

Elements of which row or column of the first matrix is to be multiplied with the elements of which row or column of the second matrix to obtain which element of which row/column of the product matrix, it is very troublesome to remember for the learners. At this point he felt helpless.

From then he was in search of an easy procedure to satisfy the students and me also. He went through different books (Indian and foreign publications), and consult senior teachers again and again. But he was always unhappy and discontented.

To invent higher theory, to solve some internationally unsolved problem with innovative ideas are research works. It is known to all. But also, to make the ideas/lessons clear to the students with some innovative processes is not less than a research work. It helps the future laureates to grow gradually by learning the basics of mathematics in simpler form.

At last, on a fine morning in winter of Dec, 2000, an idea came to my mind. Immediately, he noted down the process and tried to solve many sums. From then he started to solve the matrix - multiplication problems in my classes with the help of this process. Even the students of post-graduation were overwhelmed and told me that no other teacher had described them the matrix multiplication in such an easy way earlier.

\section{Effects on Society (Specially to Student Community)}

Any scholar/student in Mathematics, economics or in management curriculum wants to find out only one element of the product matrix for his research work he can do it very easily without computing the total matrix. Not only that, if any one learns this procedure, he can remember it even after few years of completing his studies.

Author think it will help all the students and teachers of science stream all over the world to compute the matrix-multiplication easily and smoothly. Hope, all teachers will describe Matrix-multiplication to their students in this manner from now.

After thinking and re-thinking he came to the conclusion that the process should be named as "The Rule of Vacancies". It will enhance teachers' impact on Mathematics achievement for all students. The usual existing method is O.K. for experts. But if we teach the beginners with that method they will be afraid of matrix-multiplication. It is his feeling as teacher. The students are taking the new method without fear.

\section{The Rule of Vacancies for Matrix-Multiplication}

Let us take two matrices:

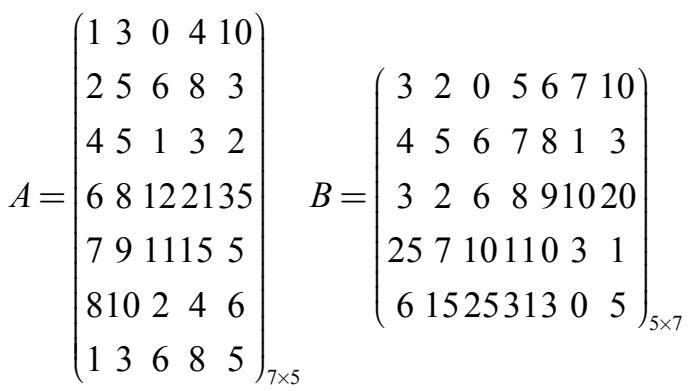

We want to find A X B

\section{Solution}

Here $\mathrm{A}$ and $\mathrm{B}$ are taken so that $\mathrm{A} \times \mathrm{B}$ is possible and let $\mathrm{A} \times \mathrm{B}=\mathrm{C}$. Then it is obvious that $C$ must be of order $7 \times 7$. i.e., In $C$ there will be 49 elements [1-4].

We do not multiply the two matrices as usual method. But think way.

Step 1

Before multiplying, we just write the metrix C with 49 Vacancies/ Vacant positions like:

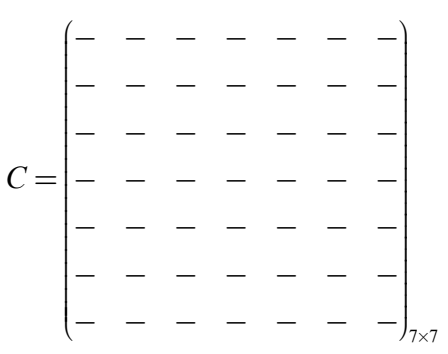

Step 2

*Corresponding author: Surajit Bhattacharyya, Professor, Seth Anandram Jaipuria College University of Calcutta, West Bengal, India, Tel: +919831238071/+917890419536; E-mail: surajit_bhattacharyya@yahoo.com

Received August 23, 2018; Accepted September 22, 2018; Published October 01, 2018

Citation: Bhattacharyya S (2018) Classical Algebra: Matrix Multiplication (The Rule of Vacancies). J Phys Math 9: 288. doi: 10.4172/2090-0902.1000288

Copyright: ( 2018 Bhattacharyya S. This is an open-access article distributed under the terms of the Creative Commons Attribution License, which permits unrestricted use, distribution, and reproduction in any medium, provided the original author and source are credited. 


$$
C=\left(\begin{array}{ccccccc}
- & - & - & - & - & - & - \\
- & - & - & - & - & - & - \\
- & Y & - & - & - & - & - \\
- & - & - & - & - & - & - \\
- & - & - & X & - & - & - \\
- & - & - & - & - & - & - \\
- & - & - & - & - & - & -
\end{array}\right)_{7 \times 7}
$$

Now suppose we want to find out vacancy where the element is X, as shown in the figure. Then first of all we have to identify its position. Here position of vacancy of $\mathrm{X}$ is $(5,4)$ i.e., 5 th row and 4 th column. Then to find out $\mathrm{X}$ we have to multiply elements of 5 th row of $\mathrm{A}$ with the elements of 4 th column of B.

Now again, we want to find out the vacancy Y. We have to find out its position first. Since its position is $(3,2)$, we have to multiply the elements of 3rd row of A with the elements of 2 nd Column of B [5-7].
In the similar way we can calculate all elements of $\mathrm{C}$ (one by one, by filling up the vacancies) to complete the matrix $\mathrm{C}$.

If $A$ is a matrix of order $100 \times 50$ and $B$ is matrix of order $50 \times 30$. Then $\mathrm{A} \times \mathrm{B}=\mathrm{C}$ will be of order $100 \times 30$ (it is known to all). In such a big multiplication, if we want to calculate any one element as required, without computing the total $100 \times 30$ elements of $\mathrm{C}$, we can use the "Rule of Vacancies" to get the answer very easily and quickly, without any confusion. This process is applicable to any type of matrix and easy to remember for the students.

\section{References}

1. Das AN. Advanced Higher Algebra (3rdedn), NCBA.

2. Chakravorty JG, Ghosh PR. Advanced Higher Algebra. (11thedn), U.N Dhur and Sons Pvt Ltd.

3. Thomas WH (1974) Algebra. Springer.

4. Dummit DS, Foote RM. Abstract Algebra. (3rdedn).

5. Hadley G (1961) Linear Algebra. Addison-Wesley Publishing Company Inc.

6. Mapa SK (2011) Higher Algebra. (8thedn), Levant Books, pp: 1-333.

7. Paria G. Classical Algebra. Courier Corporation. 